\title{
Pengaruh Permainan Konstruktif dan Percobaan Sains terhadap Kreativitas Anak Usia 5-6 Tahun
}

\author{
Suci Aulia Sari ${ }^{\circledR}$, Puji Yanti Fauziyah ${ }^{2}$ \\ Pendidikan Anak Usia Dini, Universitas Negeri Yogyakarta, Indonesia(1) \\ Pendidikan Luar Sekolah, Universitas Negeri Yogyakarta, Indonesia(2) \\ DOI: $10.31004 /$ obsesi.v6i4.1977
}

\begin{abstract}
Abstrak
Kreativitas anak sangat penting ditanamkan sejak dini. Penelitian ini mengemukakan pengaruh permainan konstruktif dan percobaan sains terhadap kemampuan kreativitas anak. Jenis penelitian yang digunakan adalah quasy eksperiment dengan desain Posttest Only Control Group Design, dengan teknik pengambilan sampel yaitu teknik random sampling. Pengumpulan data berupa test dan dokumentasi. Teknik analisis data penelitian menggunakan analisis varians Manova. Hasil penelitian menunjukkan bahwa terdapat perbedaan kreativitas pada anak yang mengikuti permainan konstruktif dan percobaan sains. Melalui hasil penelitian ini dapat diperoleh suatu permainan dan percobaan yang efektif dapat meningkatkan kreativitas anak usia dini.
\end{abstract}

Kata kunci: permainan konstruktif; percobaan sains; kreativitas anak usia dini.

\begin{abstract}
Creativity in children is very important to instill from an early age. This study suggests the effect of constructive games and science experiments on children's creative abilities. The type of research used is a quasi-experimental design with Posttest Only Control Group Design, with a random sampling technique. Collecting data in the form of tests and documentation. The research data analysis technique used Manova analysis of variance. The results showed that there were differences in creativity in children who participated in constructive games and science experiments. Through the results of this study, it is possible to obtain an effective game and experiment that can increase the creativity of early childhood.
\end{abstract}

Keywords: constructive games; science experiments; creativity early childhood.

Copyright (c) 2022 Suci Aulia Sari, Puji Yanti Fauziyah

$\triangle$ Corresponding author :

Email Address : auliasari.suci@gmail.com (Aceh Utara, Indonesia)

Received 19 October 2021, Accepted 12 December 2021, Published 17 January 2022

\section{PENDAHULUAN}

Pendidikan Anak Usia Dini (PAUD) begitu penting, karena pendidikan manusia di lima tahun pertama sangat menentukan kepuasan pribadi di kemudian hari (Gale, 2020). Pendidikan berupaya untuk mendorong anak dalam menghadapi masalah-masalah kehidupan. Pendidikan juga merupakan tempat yang menyediakan yang memfasilitasi pertumbuhan dan perkembangan anak usia dini. 
Pendidikan anak usia dini merupakan salah satu bentuk pendidikan yang menitikberatkan pada peletakan dasar pertumbuhan dan perkembangan anak secara menyeluruh baik fisik, psikomotorik, psikologis, maupun sosial yang ada dalam diri anak. Hal ini berarti pendidikan anak usia dini mempunyai tugas yang mulia yaitu mengembangkan berbagai potensi yang dimiliki oleh anak agar kelak dapat menyesuaikan diri dengan lingkungannya. Secara khusus tujuan pendidikan anak usia dini adalah membentuk anak yang berkualitas, berkembang sesuai tingkatannya sehingga memiliki kesiapan untuk memasuki pendidikan dasar dan membantu menyiapkan anak untuk mampu belajar di sekolah. Mengacu pada Permendikbud Nomor 146 Tahun 2014 tentang kurikulum 2013 Pendidikan Anak Usia Dini, yang dimaksud Pendidikan Anak Usia Dini adalah suatu upaya pembinaan yang ditujukan kepada anak sejak lahir sampai dengan usia enam tahun yang dilakukan melalui rangsangan pendidikan untuk membantu pertumbuhan dan perkembangan jasmani dan rohani agar anak memiliki kesiapan belajar dalam memasuki pendidikan lebih lanjut (Musdalifah et al., 2020).

Menurut Gardner berpendapat bahwa, kecerdasan anak bukan hanya diukur melalui tes tulis semata tetapi lebih tepat dengan cara bagaimana anak memecahkan permasalahan dalam kehidupan nyata (Forsythe, 2019). Dengan demikian, mereka juga dibekali kreativitas. Alam memberikan kepada setiap anak perangkat untuk mengarungi kehidupan dengan bekal itu. Bekal alam memberikan kecukupan bagi manusia untuk mencapai kecakapan hidup. Pendidikan, pada hakikatnya, memiliki tujuan yang hakiki yakni humanisasi. Pendidikan memiliki makna dasar, memanusiakan manusia, membuat manusia kembali pada fitrahnya. Salah satunya adalah dengan mengembalikan manusia menjadi cerdas dan kreatif guna menjangkau perkembangan hidup yang penuh nilai-nilai kemanusiaan (Husna H., 2017).

Menurut James J. Gallagher (Gale, 2020) mengatakan bahwa kreativitas merupakan suatu proses mental yang dilakukan individu berupa gagasan ataupun produk baru, atau mengkombinasikan antara keduanya yang pada akhirnya akan melekat pada dirinya. Kreativitas dapat diartikan sebagai suatu kemampuan untuk menciptakan suatu produk baru. Kreativitas adalah kemampuan seseorang untuk melahirkan sesuatu yang baru baik berupa gagasan maupun karya nyata yang relative berbeda dengan apa yang telah ada sebelumnya.

Anak yang kreatif mempunyai tiga ciri, yaitu: originality, mempunyai pemikiran yang asli atau original. Flexibility (keluwesan), yaitu kemampuan untuk menghasilkan berbagai macam ide guna memecahkan suatu masalah di luar katagori yang biasa (Pande Wayan, 2019) menunjukkan kelancaran proses berfikir (Fluency). Dengan tiga ciri utama ini, anak akan mampu menghasilkan sesuatu yang tidak sederhana dan berbeda dari peserta didik.(Juliana et al., 2018)

Dalam perkembangan seorang anak banyak keterampilan dan pengetahuan yang dimilikinya yang diperoleh melalui belajar dan bermain. Bermain merupakan pekerjaan masa kanak-kanak dan cermin pertumbuhan anak untuk mengembangkan kemampuan anak sebelum bersekolah. bermain merupakan cara yang paling alamiah untuk menemukan lingkungan orang lain yang dilakukan demi kesenangan tanpa mempertimbangkan hasil akhir.

Peran kreativitas semakin terasa dan merupakan keniscayaan tatkala kita memasuki abad 21, yang antara lain ditandai oleh perubahan yang sangat cepat dan tantangan yang semakin kompleks (Iskamto, 2020). Kreatifitas dimiliki semua individu walaupun dengan derajat yang berbeda-beda, dapat dipelajari, dimanipulasi dengan sengaja, dan perlu dikembangkan. Pengembangan kreativitas yang dilakukan di TK bervariasi, bahkan satu hari banyak kreativitas yang dapat dikembangkan dengan berbagai metode pembelajaran yang dilakukan secara integratif. 
Menurut Astuti (di dalam Renoir, 2019)menyatakan bahwa orang-orang kreatif dengan talenta khusus itu belum tentu dapat mengaktualisasikan dirinya. Sebaliknya, pada umumnya orang-orang kreatif yang dapat mengaktualisasikan dirinya cenderung lebih fleksibel dalam aspek kehidupannya dan produktif, namun belum tentu mempunyai bakat yang luar biasa seperti seni dan sains.

Bermain dapat memicu kreativitas anak untuk meningkatkan kemampuan anak dalam menghadapi kehidupannya yang mengacu pada proses yang digunakan untuk mengekspresikan imajinasi, perasaan dan gagasannya dengan cara yang lebih memuaskan dirinya. Oleh sebab itu peran orang tua dan orang yang ada disekitarnya sangat penting agar anak terdorong untuk mengekspresikan dirinya secara baik.

Untuk dapat mengembangkan kreativitas anak perlu diberikan permainan yang sesuai dengan usia anak dan dapat merangsang kreativitas anak. Salah satu permainan yang dapat meningkatkan kreativitas anak adalah permainan konstruktif. Selain itu Santrock menyatakan bahwa "permainan konstruktif adalah permainan yang terjadi ketika anakanak melibatkan diri dalam suatu kreasi atau konstruksi suatu produk atau suatu pemecahan masalah yang merupakan hasil ciptaan sendiri"(Saripudin et al., 2020). Seperti membuat rumah-rumahan dengan balok kayu atau potongan lego, menggambar, menyusun kepingan kepingan kayu bergambar dan semacamnya. Jadi permainan konstruktif adalah permainan yang terjadi ketika anak- anak melibatkan diri dalam suatu kreasi atau konstruksi suatu produk atau suatu pemecahan masalah yang merupakan hasil ciptaan sendiri.

Selain permainan konstuktif, bermain sains pada anak juga akan mengandung dan menumbuhkan kreativitas dalam bertanya pada anak. Lingkungan belajar sains akan berpengaruh terhadap cara berpikir kreatif anak dan imajinasi anak dalam mengaktulisasikan dirinya pada saat kegiatan pembelajaran. Eshach and Fried menyatakan bahwa pembelajaran sains bagi anak usia dini dapat memberikan pengalaman positif bagi anak yang membantu dirinya untuk mengembangkan pemahaman tentang suatu konsep sains, mengembangkan kemampuan berpikir, menanamkan sikap yang positif, dan memberikan landasan yang kuat untuk pengembangan konsep sains di jenjang pendidikan selanjutnya (Bucciol et al., 2011). Dengan melakukan suatu eksperimen sains bersama anak, anak mengenal konsep sains tidak hanya sebatas teori tetapi sekaligus mengajak anak berpikir dengan mengutarakan pertanyaan seperti : apa, kapan, siapa, sehingga anak mendapatkan jawabannya sendiri melalui kegiatan ekperimen yang anak lakukan.

Kreativitas anak akan tumbuh dan berkembang melalui berbagai pengalaman ketika anak dikelompok bermain atau ditaman kanak-kanak (Payudi et al., 2017). Perlu diketahui, daya kreativitas antara anak yang satu dengan anak yang lainnya berbeda karena kreativitas sifatnya sangat pribadi dan menjadi diri sendiri serta mengekspresikan diri sendiri. Kreativitas akan tumbuh dan muncul pada diri anak apabila dalam suatu kegiatan tersebut memiliki unsur seni yang dapat menarik minat dan perhatiannya untuk segera bermain dan mencobanya

Berdasarkan realita tersebut, maka pendidikanlah yang mengemban tugas untuk dapat mengembangkan potensi kreatif yang dimiliki anak tersebut. Dengan potensi kreativitas alami yang dimilikinya, maka anak akan senantiasa membutuhkan aktivitas yang syarat dengan ide-ide kreatif. Mereka perlu mendapatkan pembinaan yang tepat yang memungkinkan mereka untuk mengembangkan potensi dan kemampuannya itu secara optimal, yang pada akhirnya diharapkan kemampuannya tersebut dapat berguna bagi dirinya, keluarga, dan masyarakat pada umumnya.

Berdasarkan pengamatan awal pada TK Kecamatan Dewantara didapatkan suatu gambaran bahwa terdapat 22 TK yang terdiri dari 739 anak kelompok B dimana pada salah satu kegiatan di TK Kecamatan Dewantara, peneliti melihat cara guru mengembangkan kreativitas anak dengan cara melakukan kegiatan kolase biji-bijian bersama anak. Pada kegiatan tersebut guru meminta anak melakukan kegiatan kolase sesuai permintaan guru. Setelah anak melakukan permintaan guru, maka kegiatan kolase biji-bijian selesai. 
Berdasarkan hal tersebut anak menjadi tidak kreatif dikarenakan guru membatasi kegiatan anak, sehingga anak hanya mengikuti permintaan guru dan anak tidak dapat melalukan ideide kreatif yang dimiliki anak selama kegiatan berlangsung.

Berdasarkan observasi penulis di TK yang berada di wilayah Kecamatan Dewantara, bahwa permainan konstruktif dan pembelajaran sains belum diaplikasikan untuk mempengaruhi kreativitas anak. Tujuan penelitian ini adalah Pengaruh permainan konstruktif dan percobaan sains terhadap kreatifitas anak kelompok B di TK Kecamatan Dewantara.

\section{METODOLOGI}

Penelitian ini merupakan pendekatan kuantitatif dan jenis penelitian Quasy Experiment. Desain dalam penelitian ini adalah Posttest Only Control Group Design. Rancangan dapat dilihat pada gambar 1.

$$
\begin{aligned}
& \mathrm{R}(\mathrm{X}) \rightarrow \mathrm{O}_{1} \\
& \mathrm{R} \rightarrow \mathrm{O}_{2}
\end{aligned}
$$

\section{Gambar 1. Rancangan Penelitian}

Keterangan pada gambar $1, \mathrm{R}$ merupakan random, $\mathrm{O}_{1}$ adalah posttest kelompok eksperimen, $\mathrm{O}_{2}$ adalah posttest kelompok kontrol dan $\mathrm{X}$ adalah Perlakuan dengan permainan konstruktif dan percobaan sains. Alasan utama peneliti tidak memakai pretest karena selain pretest memiliki keunggulan juga memiliki kelemahan antara lain dengan adanya pretest, anak yang diberikan soal pretest akan mengantisipasi saat diberikan soal posttest, sehingga nilai posttest anak dapat dipengaruhi karena dalam penelitian ini menggunakan tes lisan yang sama bila dilakukan pretest maupun posttest, sehingga untuk mendapatkan nilai yang murni dari penelitian ini, peneliti tidak menggunakan nilai pre-test. Pembelajaran pada kelas kontrol dilakukan dengan penggunaan media mewarnai. Pada kelas eksperimen ini anak diajak bermain konstruktif dan percobaan sains. Selanjutnya diamati perkembangan kreativitas anak pada kedua kelas.

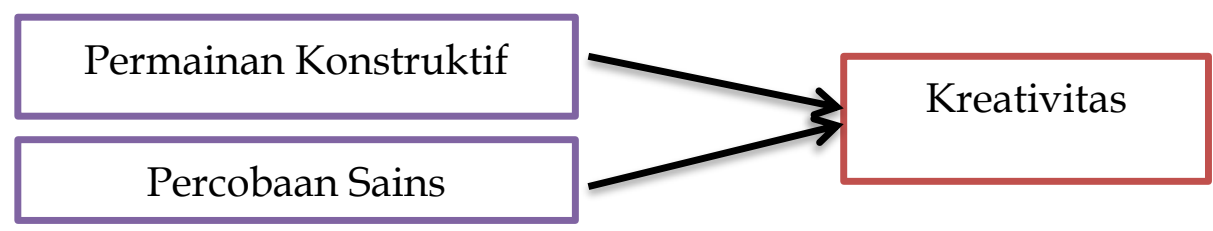

Gambar 2. Hubungan antara Variabel-Variabel Penelitian

Adapun yang menjadi variable dalam penelitian ini adalah:

1. Variable bebas $(X)$ : Permainan konstruktif dan percobaan sains

2. Variable terikat $(\mathrm{Y})$ : Perkembangan kreativitas anak usia 5-6 tahun

Tempat penelitian ini dilakukan di TK Kecamatan Dewantara pada semester ganjil bulan Agustus-September 2021. Populasi peneliti ini adalah 739 anak Kelompok B dan sampel dalam penelitian ini peneliti mempersempit populasi dengan pengambilan sampel yang dilakukan menggunakan teknik random sampling yaitu jumlah seluruh anak Kelompok B sebanyak 260 anak dengan menghitung ukuran sampel yang dilakukan dengan menggunakan rumus Slovin. Teknik pengumpulan data yang digunakan peneliti adalah observasi.

Untuk instrumen penelitian, peneliti menggunakan validitas dengan rumus Gregory dengan hasil perhitungan validitas instrument kreativitas dalam permainan konstruktif dan percobaan sains dengan menggunakan rumus Gregory berturut turut diperoleh sebesar 1 dan 1, maka dengan hasil berikut dikategorikan tinggi dan reabilitas dengan rumus Kappa 
Statistic dengan hasil perhitungan reliabilitas instrument kreativitas dalam permainan konstruktif dan percobaan sains dengan menggunakan rumus Kappa berturut turut diperoleh sebesar 0,467 dan 0,571. Koefisien Kappa yang diperoleh untuk kedua instrumen termasuk dalam kategori Intermediate to good. Berdasarkan hasil data tersebut maka instrumen dapat digunakan untuk penelitian. Instrumen penelitian ditunjukkan pada tabel 1 dan 2.

Tabel 1. Instrumen Kreatifitas Anak dalam Permainan Konstruktif

\begin{tabular}{|c|c|c|c|c|c|}
\hline \multirow{2}{*}{ No } & \multirow{2}{*}{ KOMPETENSI YANG DICAPAI } & \multicolumn{4}{|c|}{ Skor } \\
\hline & & BB & MB & BSH & BSB \\
\hline 1 & $\begin{array}{l}\text { Bentuk geometri yang dapat diciptakan anak ketika } \\
\text { bermain playdough }\end{array}$ & & & & \\
\hline 2 & $\begin{array}{l}\text { Anak menghasilkan bentuk kue donat dari playdough } \\
\text { dengan ukuran besar yang berbeda-beda dari temannya }\end{array}$ & & & & \\
\hline 3 & $\begin{array}{l}\text { Bentuk donat yang dihasilkan anak dari bermain } \\
\text { playdough }\end{array}$ & & & & \\
\hline 4 & $\begin{array}{l}\text { Ide-ide kreatif yang muncul pada anak dalam bermain } \\
\text { playdough berbentuk lingkaran }\end{array}$ & & & & \\
\hline 5 & $\begin{array}{l}\text { Anak menciptakan gedung bertingkat dalam waktu } \\
\text { singkat }\end{array}$ & & & & \\
\hline 6 & Ide (bangunan) yang dibuat anak ketika bermain balok & & & & \\
\hline 7 & $\begin{array}{l}\text { Anak membuat bentuk rumah yang berbeda dengan } \\
\text { temannya pada bermain balok }\end{array}$ & & & & \\
\hline 8 & $\begin{array}{l}\text { Anak menyelesaikan permainan puzzle angka dengan } \\
\text { teratur dan rapi }\end{array}$ & & & & \\
\hline
\end{tabular}

Tabel 2. Instrumen Kreatifitas Anak dalam Percobaan Sains

\begin{tabular}{clcc}
\hline No & \multicolumn{1}{c}{ KOMPETENSI YANG DICAPAI } & \multicolumn{2}{c}{ Skor } \\
& \multicolumn{1}{c}{ Bnak memberi contoh benda-benda yang terapung } & & \\
MB & BSH & BSB \\
\hline 2 & $\begin{array}{l}\text { Anak memberi contoh benda-benda yang } \\
\text { tenggelam di air }\end{array}$ \\
3 & $\begin{array}{l}\text { Anak merasa senang bermain benda-benda } \\
\text { terapung dan tenggelam di air }\end{array}$ \\
4 & $\begin{array}{l}\text { Anak menanam biji kacang hijau dengan benar } \\
\text { sesuai dengan video yang ditampilkan } \\
\text { Anak menceritakan kembali proses percobaan } \\
\text { telur mengapung }\end{array}$ \\
&
\end{tabular}

Teknik analisis data yang akan digunakan dalam penelitian ini statistik nonparametric. Uji statistik digunakan untuk menguji penolakan atau penerimaan hipotesis nol, dengan syarat bahwa sampel itu homogen dan berdistribusi normal. Nilai dari hasil tes yang diperoleh pada kelas eksperimen dan kelas kontrol disusun dalam tabel distribusi frekuensi. Dalam penelitian ini menggunakan uji normalitas data dan uji hipotesis. Setelah mendapatkan nilai selanjutnya menentukan kriteria sesuai nilai yang didapat.

\section{HASIL DAN PEMBAHASAN}

Uji hipotesis dilakukan dengan metode statistika dengan formula Manova satu jalur, setelah hasil post test kreativitas anak usia dini memenuhi uji prasyarat. Uji prasyarat yang dilakukan adalah uji normalitas dan uji homogenitas. Uji normalitas dilakukan untuk mengetahui apakah data berdistribusi normal atau tidak normal pada kelas eksperimen dan 
kelas kontrol. Uji normalitas pada penelitian ini menggunakan bantuan program SPSS 21.0 for windows dengan menggunakan lajur Kolmogorov-Smirnov. Kriteria yang dipakai adalah jika nilai signifikansi $>0,05$ maka data berdistribusi normal, sedangkan jika nilai signifikansi $<0,05$ menunjukkan data tidak berdistribusi normal. Tabel 3 disajikan hasil uji normalitas data penelitian.

Tabel 3. Hasil Uji Normalitas

\begin{tabular}{lccc}
\hline \multicolumn{1}{c}{ Kelas } & Permainan Konstruktif & Percobaan Sains & Keterangan \\
\hline Kontrol & 0,192 & 0,196 & Distribusi Normal \\
Eksperimen & 0,200 & 0,200 & Distribusi Normal \\
\hline
\end{tabular}

Tabel 3 di atas menunjukkan hasil uji normalitas kelas kontrol maupun eksperimen pada permainan konstruktif dan percobaan sains bahwa data tersebar normal pada semua unit analisis, Nilai signifikansi pada uji statistic Kolmogorov-Smirnov, menunjukkan nilai signifikansi lebih besar dari 0,05. Maka dapat dikatakan bahwa skor permainan konstruktif dan percobaan sains pada anak usia dini pada kelas kontrol maupun kelas eksperimen berdistribusi normal.

Uji homogenitas dimaksudkan untuk mengetahui data yang dianalisis homogen atau tidak. Kriteria pengujian berasal dari populasi data yang homogen jika nilai signifikansinya lebih besar dari 0,05. Pengujian homogenitas untuk uji multivariat menggunakan uji Box"s M test. Analisis uji homogenitas yang dilakuan dengan bantuan program SPSS 22 for windows.

\section{Tabel 4. Hasil Uji Homogenitas}

\begin{tabular}{|c|c|}
\hline \multicolumn{2}{|c|}{ Box's Test of Equality of Covariance Matricesa } \\
\hline Box's M & 601 \\
\hline F & 197, \\
\hline df1 & 3 \\
\hline df2 & 2949120,000 \\
\hline Sig. & 899 \\
\hline
\end{tabular}

Data pada tabel 4, menunjukkan hasil angka signifikansi sebesar 0,899 lebih besar dari 0,05 . Artinya bahwa data permainan konstruktif dan percobaan sains pada anak usia dini memiliki sebaran data yang homogen. Berdasarkan uji prasyarat, menunjukkan data yang diperoleh berdistribusi normal, dan varian data homogen.

Setelah uji prasyarat terpenuhi, maka selanjutnya dilakukan analisis uji hipotesis. Penelitian ini terdiri dari tiga hipotesis yang harus diuji kebenarannya. Analisis dilakukan dengan bantuan software SPSS 22.0 for windows. Adapun kriteria keputusannya yaitu $\mathrm{H}_{1}$ diterima jika nilai sig $\leq 0,05$. Hasil uji hipotesis $1 \& 2$ disajikan pada Tabel 5.

Berdasarkan tabel 5, hasil uji hipotesis 1 dan 2 dianalisis dengan uji univariat sebagai berikut; (1) Terdapat pengaruh signifikan permainan konstruktif pada kreativitas anak kelompok B di TK Kecamatan Dewantara, hal tersebut ditunjukkan dengan nilai F sebesar 230,483 dan nilai sig sebesar 0,000<0,05 berarti $\mathrm{H}_{1}$ diterima, (2) ada pengaruh signifikan percobaan sains terhadap kreativitas anak kelompok B di TK Kecamatan Dewantara, hal tersebut ditunjukkan dengan nilai F sebesar 529,297 dan nilai sig sebesar 0,000<0,05 berarti $\mathrm{H}_{1}$ diterima. 
Tabel 5. Uji Hipotesis 1 dan 2

Tests of Between-Subjects Effects

\begin{tabular}{ll|c|c|c|c|c|r}
\hline Source & $\begin{array}{l}\text { Dependent } \\
\text { Variable }\end{array}$ & $\begin{array}{c}\text { Type III Sum of } \\
\text { Squares }\end{array}$ & df & $\begin{array}{c}\text { Mean } \\
\text { Square }\end{array}$ & F & Sig. & \multicolumn{2}{c}{$\begin{array}{c}\text { Partial Eta } \\
\text { Squared }\end{array}$} \\
\hline Corrected & P.K & $3987,692^{\mathrm{a}}$ & 1 & 3987,692 & 230,483 &, 000 &, 643 \\
Model & P.S & $2918,892^{\mathrm{b}}$ & 1 & 2918,892 & 529,297 &, 000 &, 805 \\
\hline
\end{tabular}

a. R Squared $=, 643$ (Adjusted R Squared $=, 640$ )

b. R Squared $=, 805$ (Adjusted R Squared $=, 804$ )

Setelah hipotesis pertama dan kedua dianalisis dengan uji univariat, selanjutnya hipotesis ketiga dianalisis dengan uji multivariat (Manova). Uji multivariat dilakukan untuk melihat pengaruh permainan kostruktif dan percobaan sains terhadap kreativitas secara bersamaan. Analisis dilakukan dengan bantuan software SPSS 22.0 for windows. Adapun kriteria keputusannya yaitu $\mathrm{H}_{1}$ diterima jika nilai sig $\leq 0,05$. Data hasil analisis ditunjukkan pada Tabel 6.

Tabel 8. Uji Hipotesis 3

Multivariate Tests ${ }^{\mathrm{a}}$

\begin{tabular}{|c|c|c|c|c|c|c|c|}
\hline Effect & & Value & $\mathrm{F}$ & $\begin{array}{c}\text { Hypothesis } \\
\text { df }\end{array}$ & Error df & Sig. & $\begin{array}{c}\text { Partial Eta } \\
\text { Squared }\end{array}$ \\
\hline \multirow[t]{4}{*}{ KELAS } & $\begin{array}{l}\text { Pillai's } \\
\text { Trace }\end{array}$ & 852 & $364,981^{b}$ & 2,000 & 127,000 & , 000 & 852 \\
\hline & $\begin{array}{l}\text { Wilks' } \\
\text { Lambda }\end{array}$ & 148 & $364,981^{b}$ & 2,000 & 127,000 & ,000 & 852 \\
\hline & $\begin{array}{l}\text { Hotelling' } \\
\text { s Trace }\end{array}$ & 5,748 & $364,981^{b}$ & 2,000 & 127,000 &, 000 & 852 \\
\hline & $\begin{array}{l}\text { Roy's } \\
\text { Largest } \\
\text { Root }\end{array}$ & 5,748 & $364,981^{b}$ & 2,000 & 127,000 & ,000 & 852 \\
\hline
\end{tabular}

a. Design: Intercept + KELAS

b. Exact statistic

Pada tabel 6, hasil analisis menunjukkan bahwa hasil uji manova dapat dilihat pada nilai Hotelling"s Trace sebesar 5,748. Nilai F sebesar 364,98 dan nilai sig sebesar 0,000<0,05. Hal ini berarti bahwa $\mathrm{H}_{1}$ diterima karena nilai sig< 0,05. Dapat diinterpretasikan bahwa terdapat pengaruh signifikan permainan konstruktif dan percobaan sains terhadap kreativitas anak kelompok B di TK Kecamatan Dewantara secara simultan.

Permainan konstruktif dapat mempengaruhi kreativitas anak. Melalui permainan konstruktif, anak bebas mengembangkan daya imajinasinya, mendorong anak untuk mampu memecahkan masalah secara kreatif dan memberi peluang bagi pencapaian untuk membangun rasa percaya diri anak. Sejalan dengan pendapat Santrock yang menyatakan bahwa permainan konstruktif adalah permainan yang terjadi ketika anak- anak melibatkan diri dalam suatu kreasi atau konstruksi suatu produk atau suatu pemecahan masalah yang merupakan hasil ciptaan sendiri (Saripudin et al., 2020).

Permainan konstruktif yang dilakukan menggunakan berbagai benda untuk menciptakan suatu hasil karya tertentu, dan gunanya untuk meningkatkan kreativitas, melatih motorik halus, melatih konsentrasi, ketekunan, dan daya tahan. Salah satu cara 
mempengaruhi kreativitas anak yaitu dengan menggunakan permainan konstruktif dengan mengenalkan lebih dekat kegiatan bermain konstruktif untuk anak, karena dengan bermain konstruktif anak dapat membuat hasil karya bentuk benda sesui dengan imajinasinya dengan memberi inisiatif yang berbeda (Lubart et al., 2019). Permainan yang dilakukan peneliti pada permainan konstruktif yaitu puzzle, playdough, dan balok. Menurut (Barashkov \& Gubinelli, 2021) menyatakan yang termasuk kedalam permainan konstruktif yaitu balok, puzzle, dan playdough.

Percobaan sains akan mengajak anak untuk mencoba suatu kegiatan yang belum pernah anak lakukan sebelumnya, ini akan menjadi pengalaman baru untuk anak yang meningkatkan kreativitasnya. Dalam aktifitas melakukan percobaan sains akan timbul banyak pertanyaan dari dalam diri anak yang diharapkan dapat menggali potensi kreativitas yang ada dalam diri anak dengan cara menumbuhan kreativitas dalam bertanya yang tinggi terhadap sesuatu, sehingga anak memiliki keberanian untuk mencoba sesuatu yang baru (Calmet et al., 2021).

Percobaan yang dilakukan peneliti pada percobaan sains yaitu benda terapung dan tenggelam, telur mengapung, dan menanam biji kacang hijau. Ada beberapa konsep sains yang dapat dipelajari anak kelompok B (Senabre et al., 2018) yaitu benda-benda dimasukkan ke dalam air (terapung dan tenggelam), telur mengapung, dan menanam biji kacang hijau. Topik pembelajaran sains atau bahan ajar sains berangkat dari lingkungan sekitar (Lakomý et al., 2019). Benda-benda dalam pengenalan sains memanfaatkan lingkungan sekitar.

Kreativitas anak berkaitan dengan imajinasi atau manifestasi kecerdikan dalam pencarian yang bernilai (Hadzigeorgiou et al., 2012). Kreativitas anak disebut kemampuan yang mencerminkan kelancaran, keluwesan, dan orisinalitas dalam berfikir serta kemampuan yang mencerminkan untuk mengkolaborasi (mengembangkan, memperkaya) suatu gagasan. Kreativitas anak perlu dilatih sejak dini supaya di masa mendatang anak akan tumbuh menjadi orang yang terampil dan cekatan dalam melakukan segala aktivitas dan mampu menghadapi permasalahan hidup. Kreativitas merupakan suatu proses mental yang dilakukan individu berupa gagasan ataupun produk baru, atau mengkombinasikan anatara keduanya yang pada akhirnya akan melekat pada dirinya (Rahayu et al., 2020)

\section{SIMPULAN}

Terdapat pengaruh signifikan permainan konstruktif pada kreativitas anak kelompok B di TK Kecamatan Dewantara, hal tersebut ditunjukkan dengan nilai F sebesar 230,483 dan nilai sig sebesar $0,000<0,05$ berarti $\mathrm{H}_{1}$ diterima. Terdapat pengaruh signifikan percobaan sains terhadap kreativitas anak kelompok B di TK Kecamatan Dewantara, hal tersebut ditunjukkan dengan nilai $\mathrm{F}$ sebesar 529,297 dan nilai sig sebesar $0,000<0,05$ berarti $\mathrm{H}_{1}$ diterima. Terdapat pengaruh signifikan permainan konstruktif dan percobaan sainst terhadap kreativitas anak kelompok B di TK Kecamatan Dewantara, hal tersebut ditunjukkan dengan hasil analisis dengan uji Manova diperoleh F sebesar 364,98 dan nilai sig sebesar $0,000<0,05$ berarti $\mathrm{H}_{1}$ diterima, sehingga disimpulkan bahwa penggunaan permainan konstruktif dan percobaan sains berpengaruh terhadap kreativitas anak kelompok B di TK Kecamatan Dewantara.

\section{UCAPAN TERIMA KASIH}

Ucapan terima kasih penulis haturkan kepada pihak-pihak yang telah memberikan masukan dalam pelaksanaan penelitian ini, yakni; (1) Rektor Universitas Negeri Yogyakarta yang telah memberikan izin dan memfasilitasi penelitian. (2) Direktur Pascasarjana Universitas Negeri Yogyakarta yang telah memberikan izin penelitian. (3 Ibu Dr. Puji Yanti Fauziyah, S.Pd., M.Pd. selaku dosen pembimbing tesis yang telah banyak memberikan arahan dalam pelaksanaan penelitian ini. Dan (5) Kepala sekolah, guru, karyawan dan peserta didik TK Kecamatan Dewantara yang telah memberikan ijin dalam pelaksanan penelitian ini. 


\section{DAFTAR PUSTAKA}

Barashkov, N., \& Gubinelli, M. (2021). The $\Phi 43$ measure via Girsanov's theorem. Electronic Journal of Probability, 26. https://doi.org/10.1214/21-EJP635

Bucciol, A., Houser, D., \& Piovesan, M. (2011). Temptation and productivity: A field experiment with children. Journal of Economic Behavior and Organization, 78(1-2). https:// doi.org/10.1016/j.jebo.2010.12.013

Calmet, C., Duc-Fortier, E., \& Tondeur, A. (2021). Terre! Une formation d'enseignants sur le dialogue créatif entre arts et sciences. Arts et Sciences, 5(2). https:// doi.org/10.21494/ISTE.OP.2021.0693

Forsythe, A. (2019). Howard Gardner. In Key Thinkers in Individual Differences. https://doi.org/10.4324/9781351026505-21

Gale, M. (2020). Preventing social isolation: A holistic approach to nursing interventions. Journal of Psychosocial Nursing and Mental Health Services, 58(7). https:// doi.org/10.3928/02793695-20200616-03

Hadzigeorgiou, Y., Fokialis, P., \& Kabouropoulou, M. (2012). Thinking about creativity in science education. Creative Education, 03(05). https://doi.org/10.4236/ce.2012.35089

Husna H., P. (2017). Pengembangan kreativitas anak usia dini dalam keluarga. Jurnal Keluarga Sehat Sejahtera, 15(2), 46-56. https:/ / doi.org/10.24114/jkss.v15i2.8774

Iskamto, D. (2020). The role of leadership and influence on employee performance in digital era. Jurnal Manajemen Bisnis, 17(4). https:// doi.org/10.38043/jmb.v17i4.2730

Juliana, J., Fatimah, F., \& Apriliyanti, A. (2018). Empowering and fostering creative industries entrepreneurs based on local wisdom of malay deli. KARSA: Journal of Social and Islamic Culture, 26(2). https://doi.org/10.19105/karsa.v26i2.1829

Lakomý, M., Hlavová, R., \& Machackova, H. (2019). Open science and the science-society relationship. Society, 56(3). https://doi.org/10.1007/s12115-019-00361-w

Lubart, T., Besançon, M., \& Barbot, B. (2019). La créativité, ressource potentielle de l'enfant et l'adolescent, à évaluer, révéler et développer. Neuropsychiatrie de l'Enfance et de l'Adolescence, 67(3). https:// doi.org/10.1016/j.neurenf.2019.02.004

Murwatiningsih, Oktarina, N., \& Witiastuti, R. (2019). The development of business creativity, business superiority, and entrepreneurship network to improve business performance. International Journal of Business and Society, 20(2).

Musdalifah, M., M., A., \& S., S. (2020). Peningkatan kreativitas anak melalui metode discovery pada pembelajaran sains di taman kanak-anak aisyiyah bustanul athfal mario. TEMATIK: Jurnal Pemikiran Dan Penelitian Pendidikan Anak Usia Dini, 6(1), 42. https://doi.org/10.26858/tematik.v6i1.14438

Pande Wayan, R. (2019). Region of creatifity industries for disabilities (balinese cultural perspective). https://doi.org/10.4108/eai.30-10-2018.2281456

Payudi, P., Ertikanto, C., Fadiawati, N., \& Suyatna, A. (2017). The development of student worksheet assisted by interactive multimedia of photoelectric effect to build science process skills. International Journal of Science and Applied Science: Conference Series, 2(1). https:// doi.org/10.20961/ijsascs.v2i1.16726

Rahayu, H., Yetti, E., \& Supriyati, Y. (2020). Meningkatkan kreativitas anak usia dini melalui pembelajaran gerak dan lagu. Jurnal Obsesi : Jurnal Pendidikan Anak Usia Dini, 5(1), 832-840. https://doi.org/10.31004/obsesi.v5i1.691

Renoir, S. (2019). Detroit: Le «tournant créatif» à partir du design? Communication, 36(1). https://doi.org/10.4000/communication.10011

Saripudin, A., Khaeriyah, E., \& Lestari, R. A. (2020). Mengembangkan kreativitas anak usia dini melalui menggambar dengan teknik inkblot. Equalita: Jurnal Studi Gender Dan Anak, 2(1). https:// doi.org/10.24235/equalita.v2i1.7058

Senabre, E., Ferran-Ferrer, N., \& Perelló, J. (2018). Participatory design of citizen science experiments. Comunicar, 26(54). https://doi.org/10.3916/C54-2018-03 https://doi.org/10.3916/C54-2018-03 